\title{
Acti-Gelß 208 as an additive for paste and hydraulic backfill
}

\author{
K Tarr Natural Resources Canada CanmetMINING, Canada \\ I Bedard Natural Resources Canada CanmetMINING, Canada \\ H Kim Active Minerals International LLC, Canada
}

\begin{abstract}
Paste technology has progressed to a widely accepted, cost-effective backfill method, and is also used extensively in surface tailings disposal. The non-segregating nature of paste makes it a very attractive option for backfilling, and its stacking behaviour due to its low water content significantly reduces the risks associated with surface tailings dam failure. While the capital and operating costs for the preparation and transportation of paste are higher than that of hydraulic fill, there are significant benefits with respect to transportation, such as reduced pipe wear and reduced risk of pipe plugging, not to mention the benefits associated with greatly reducing the water handling issues underground. From an environmental standpoint, the benefits of paste versus hydraulic fill include the ability to place more of the fine tailings fraction underground, thereby reducing the need for surface tailings storage. Another environmental benefit is the reduced risk of downstream contamination in the case of a tailings dam failure, due to the fact that disposing of the tailings in a paste form means virtually no need for liquid containment, and therefore no means for the tailings to travel downstream.
\end{abstract}

Portland cement is typically used to solidify backfill, whether paste or hydraulic. This represents a major cost in mining operations due to production and haulage costs of ordinary Portland cement. In addition, the manufacturing of cement raises environmental considerations because it produces a considerable amount of $\mathrm{CO}_{2}$ emissions. Therefore, the search for additives which allow for a reduction in the required cement content in backfill has been ongoing for decades. Acti-Gel ${ }^{\circledR 2} 28$ is a highly purified magnesium aluminosilicate that acts as a high performance anti-settling agent and rheology modifier used in a wide variety of water-based industrial applications. Studies have shown that as an additive in paste backfill, it results in improved strength and flow properties, such as friction loss and segregation.

This paper presents the results of a study conducted by Active Minerals International LLC for a South African gold mine operation in 2013, as well as the results of a study conducted by the CanmetMINING Sudbury Laboratory for Vale Canada Ltd. in Sudbury, Ontario, Canada, in 2014. The feasibility of Acti-Gel ${ }^{\circledR} 208$ as a cost-effective additive for underground paste and hydraulic backfill applications was investigated through the preparation of samples to compare the strength and flowability characteristics of standard mixes to those containing different dosages of Acti-Gel ${ }^{\circledR} 208$. It was found that at a low dosage of $0.03 \mathrm{wt} \%$, Acti-Gel ${ }^{\circledR 2} 208$ delivered enhanced performance in unconfined compressive strength tests as well as in the pilot-scale flow tests. A significant reduction in binder content could be realised with addition of Acti-Gel ${ }^{\circledR} 208$ at the gold mine operation in South Africa, as well as at the Coleman and Creighton Operations in Sudbury, Ontario, Canada. The economic benefits of such a binder reduction with respect to the Canadian operations are also discussed in this paper.

\section{Introduction}

Backfill is an integral part of an underground mining operation. Its two main purposes are safety of the underground openings and environmental remediation by use of waste material as a construction material underground. There are various sources used for backfill material; however, mines typically choose materials which are locally available and economical, such as mill tailings. Hydraulic fill has historically been 
preferred over paste fill, due to its ease of pouring; however, paste fill is seeing increased usage lately (Hartman et al. 1992). As of the late nineties, hydraulic and paste fills were equally used in the Ontario mining industry.

The non-segregating nature of paste makes it a very attractive option for backfilling, and its stacking behaviour due to its low water-content significantly reduces the risks associated with surface tailings dam failure. While the capital and operating costs for the preparation and transportation of paste are higher than that of hydraulic fill, there are significant benefits with respect to reducing water handling issues underground, as well as transportation, such as reduced pipe wear and reduced risk of pipe plugging. If there is ever a pipeline blockage, a paste fill is much less likely to settle in the pipe. In contrast, hydraulic fill typically settles rapidly in the pipe, compounding the issue of the pipe blockage.

Backfill velocity is linked to the effect of solids concentration. At low solids concentrations, high velocities must be maintained to achieve optimal flow regimes. Ackim (2011) also stated that hydraulic slurry backfill must be transported in pipelines at high velocities in order to maintain turbulent flow to keep its solid phase in suspension. When finer particle fractions of hydraulic backfill slurry settle at considerable slower rates than the coarse fractions, the phenomenon is called, segregation or stratification. Backfill material in the stope will show grading if fine fractions are carried away in the decant water. Segregation causes the fill mass to be non-homogeneous and may result in an overall reduction in fill strength due to the creation of planes of weakness and areas of low binder content (Ackim 2011).

From an environmental standpoint, the benefits of paste versus hydraulic fill include the ability to place more of the fine tailings fraction underground, thereby reducing the need for surface tailings storage. It is important to note that the use of cemented paste backfill over hydraulic fill allows for about a $60 \%$ decrease in the amount of sulphidic waste that has to be disposed of on the surface, further reducing the negative environmental impact of surface tailings disposal (Benzaazoua et al. 2004). Another environmental benefit is the reduced risk of downstream contamination in the case of a tailings dam failure, due to the fact that disposing of the tailings in a paste form means virtually no need for liquid containment, and therefore no means for the tailings to travel downstream.

Backfill, regardless of the type, plays a vital role in the process of ore extraction in underground mining. Depending on the mining method used, backfill provides a working surface, stabilises stope and pillar walls, as well as the surrounding rock mass, and controls caving of stope backs. The economic feasibility of many mining techniques depends on the ability to place competent backfill in the underground voids to ensure safe working conditions. To ensure this competency, Portland cement is primarily used to solidify backfill, which represents a major cost in mining operations, due to production and haulage costs of ordinary Portland cement. In addition, the manufacturing of cement raises environmental considerations because it produces a considerable amount of $\mathrm{CO}_{2}$ emissions. Therefore, the search for alternatives or additives which allow for a reduction in the required cement content in backfill has been ongoing for decades. Some alternatives studied as full or partial replacements for Portland cement include sulphate resistant cements, artificial pozzolans, natural pozzolans, calcium sulphate substances, and sodium silicates (Tariq \& Yanful 2013).

Additives have been studied for the purpose of allowing dense fill-like materials to restart flowing after a shutdown in long distance pipeline transportation (Wang et al. 2011). The aim of the investigation by Wang et al. (2011) was to find suitable stabilising additives to prevent sedimentation during an interrupted period of pipelining. Additives which have the potential to improve rheological properties of slurry backfills, such as reducing the risk of segregation, will be even more of an asset in deep mining because of the increased distances required to transport the slurry.

Acti-Gel $^{\bullet}$ is a highly purified magnesium aluminosilicate that acts as a high performance anti-settling agent and rheology modifier used in a wide variety of water-based industrial applications. Studies have shown that as an additive in paste and hydraulic backfill, it results in improved strength and flow properties, such as lower friction loss and less segregation. 
This paper presents the results of a study conducted by Active Minerals International LLC for a gold mine operation in South Africa in 2013, as well as the results of a study conducted by the CanmetMINING Sudbury Laboratory for Vale Canada Ltd. in Sudbury, Ontario, Canada in 2014. Acti-Gel ${ }^{\circledR} 208$ was introduced to Mines Technical Support at Vale Canada Ltd. by Active Minerals International LLC in May 2013. Its two key benefits were explained as early strength and flowability improvement in backfill, and it was further explained that these benefits would bring potential binder reduction and effective sand fill transportation by improving flow and preventing pipe plugging for operational and maintenance benefits. Early strength, improvement in flow and prevention of pipe plugging could be of particular interest to Vale's deep mining operations.

\section{Approach}

\subsection{Laboratory strength determination - paste fill}

In January 2013, several batches of pastefill were prepared to determine the effect of Acti-Gel ${ }^{\circledR 208}$, at two different dosages, on the standard backfill mix at a South African gold mine operation. The raw materials were tailings and aggregate at binder contents ranging from 2 to $6.5 \mathrm{wt} \%$ ordinary Portland cement (OPC). The target slump was between 200 and $229 \mathrm{~mm}$ ( 8 and 9 in). Numerous samples for uniaxial compressive strength (UCS) determination were prepared in undrained cylindrical moulds of $100 \mathrm{~mm}$ (4 in) in diameter and $200 \mathrm{~mm}$ ( $8 \mathrm{in}$ ) in height, at curing periods ranging from three to 28 days.

\subsection{Laboratory strength determination - hydraulic fill}

A total of 12 batches of backfill were prepared representing the backfill employed at the Coleman Mine operation, at varying binder contents, flocculant dosages and Acti-Gel ${ }^{\circledR}$ contents, from which 144 cylindrical samples were prepared for determination of UCS at various curing periods. The batches were prepared by adding the materials into a propeller mixer, using a standard mixing sequence, as follows: water, tailings, sand, flocculant, binder, and Acti-Gel ${ }^{\circledast}$. The batches were then mixed for 15 minutes prior to casting. In order to achieve the desired solids content, the initial moisture content of the raw materials were taken into account when determining the amount of water to add to the mix.

Testing protocols have been developed by CanmetMINING and its partners to reflect underground conditions and reduce the amount of variability in the tests. It is necessary to determine whether samples should be prepared in drained or undrained conditions. For this study, since Coleman and Creighton Mine both employ a hydraulic fill system, drained samples of $100 \mathrm{~mm}$ (4 in) in diameter and $200 \mathrm{~mm}(8 \mathrm{in})$ in height were selected. Therefore, the moulds had perforated bases with filter paper of medium fast speed and medium crystalline retention placed in the base of the perforated cylinders to prevent loss of fines. Collars of $100 \mathrm{~mm}(4 \mathrm{in})$ in height were affixed to the moulds prior to casting in an attempt to ensure proper sample height after drainage. The UCS samples were cured on sand beds for the first 24 hours to allow the water to drain. The samples were cured in a controlled environment of $100 \%$ relative humidity and $20^{\circ}+/-3^{\circ} \mathrm{C}$.

The 12 batches of backfill were prepared at two binder contents, two flocculant dosages, and three Acti-Gel ${ }^{\circledR}$. Batches were repeated without flocculant addition to determine the effect of Acti-Gel ${ }^{\circledR}$ with and without the flocculant in the mix. For each batch, at least three repetition samples were prepared for each curing period. Curing periods included three, five, seven, 14 and 28 days.

\subsection{Pilot-scale flow properties determination - paste fill}

In early 2013, a unique pilot-scale flowability apparatus was constructed on the gold mine operation's property (Figure 1). A total of 12 new batches of backfill were prepared, at varying binder contents and Acti-Gel ${ }^{\circledR} 208$ contents. The flow properties of each batch were investigated by allowing the backfill to freefall from the hopper through the piping, while measuring flow rate. The flow test apparatus consisted of a propeller mixer followed by a transfer hopper which was located directly above a $2.8 \mathrm{~m}$ vertical section of $50 \mathrm{~mm}$ ID piping. The vertical section of pipe transitioned to a $1.8 \mathrm{~m}$ horizontal section by way of a $90^{\circ}$ 
elbow. At the end of the horizontal pipe section was a quarter turn valve to release the flow and begin the flow test. Directly following the quarter turn valve was a short section of downspout connected via a second $90^{\circ}$ elbow which discharged the slurry material.

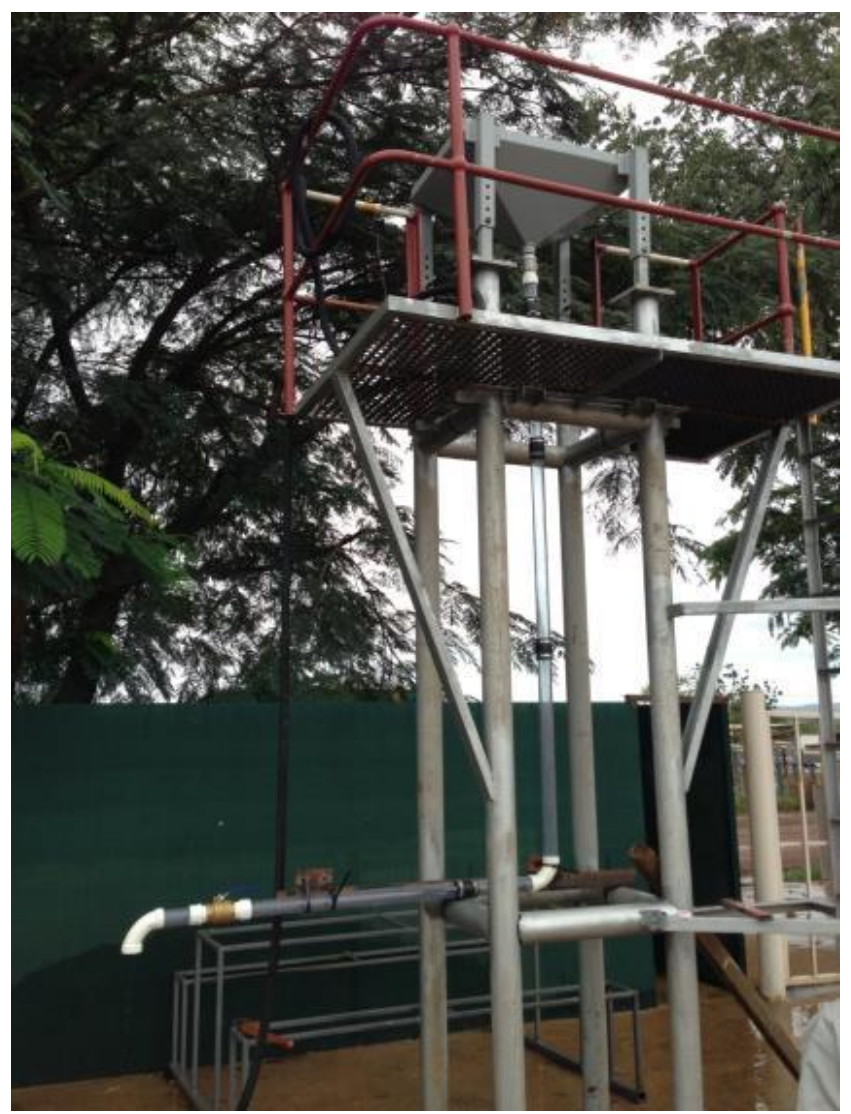

\section{Figure 1 Photograph of the paste fill pilot-scale flowability testing set-up}

Each batch consisted of approximately $100 \mathrm{~kg}$ of paste fill. The batches were prepared by adding the materials into the propeller mixer, using the same standard mixing sequence as was used for the UCS tests. During the backfill mixing time, for each batch the pipe system was filled with water from the quarter turn valve at the end of the pipe run up to the bottom of the hopper. A foam ball was used to seal the top of the pipe system and separate the water from the fill material to be tested. Following this, the backfill mixture was poured into a hopper before being released by the opening of the quarter turn valve. The fill was captured into $20 \mathrm{~L}$ pails, and the time taken to fill a volume of $13 \mathrm{~L}$ was recorded. Observations of the flow of the paste were also recorded.

\subsection{Pilot-scale flow properties determination - hydraulic fill}

In early 2014, a pilot-scale flowability apparatus, similar to the one used in the pastefill studies, was constructed in the CanmetMINING Sudbury Laboratory. A total of 12 new batches of backfill were prepared, at varying binder contents, flocculant dosages, and Acti-Gel ${ }^{\circledR}$ contents. The flow properties of each batch were investigated by allowing the backfill to free-fall from the hopper through the piping, while measuring flow rate. A schematic and photograph of the apparatus are shown in Figure 2.

Each batch consisted of approximately $75 \mathrm{~kg}$ of hydraulic fill slurry. The batches were prepared in a similar manner as in the pastefill trials. The fill was captured into $20 \mathrm{~L}$ pails, which were weighed immediately after the test. Pour times were recorded by stopwatch from the moment the valve was opened until a pre-determined time had elapsed. The volume of the pipe section was calculated to determine the amount of water in the lines to be taken out of the captured fill calculations. A video record was also taken of all tests. 


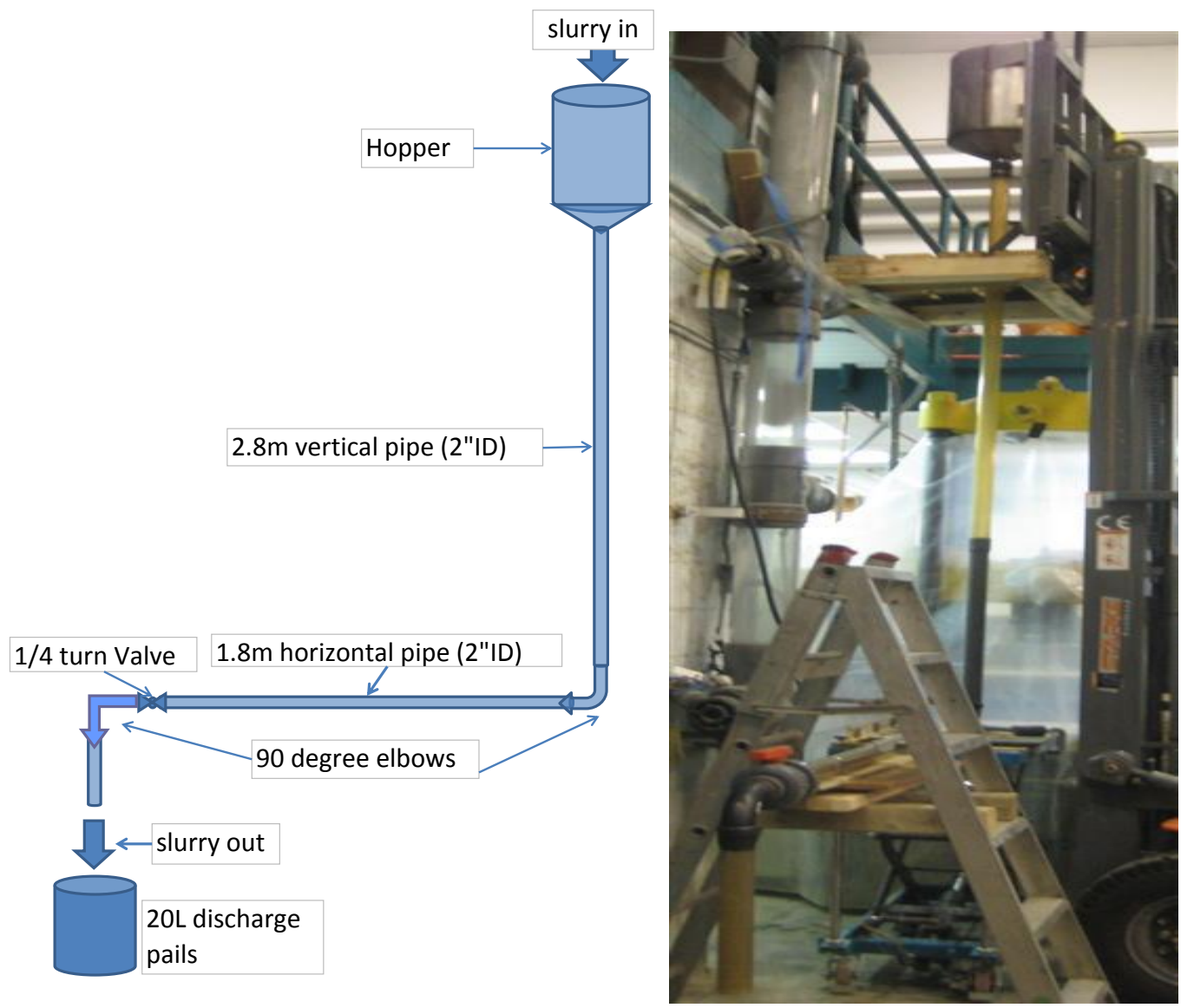

Figure 2 Schematic and photograph of the pilot-scale flow apparatus

\section{Laboratory strength determination results and discussion}

\subsection{Laboratory strength results and discussion - paste fill}

The average UCS results for the standard paste fill recipe versus those with Acti-Gel ${ }^{\circledR}$ as a function of curing time is shown in Table 1 and Figure 3. It can be seen that the average UCS was higher with the addition of Acti-Gel ${ }^{\circledR}$ at dosages of both $0.03 \mathrm{wt} \%$ and $0.05 \mathrm{wt} \%$. The target was to achieve $1 \mathrm{MPa}$ after 28 days. It would appear that with Acti-Gel ${ }^{\circledR}$ addition, $1 \mathrm{MPa}$ could be reached before 14 days. It can also be seen from Figure 3 that the samples prepared with $0.03 \mathrm{wt} \%$ Acti-Gel ${ }^{\circledR}$ returned higher strengths than those prepared with the higher dosage of 0.05 wt\% Act-Gel $^{\circledast}$.

\section{Table 1 Average UCS test results}

\begin{tabular}{ccccccccccc}
\hline & \multicolumn{10}{c}{ Average UCS (MPa) } \\
Batch \# & $\begin{array}{c}\text { Cement } \\
\text { content } \\
\text { (wt\%) }\end{array}$ & $\begin{array}{c}\text { Water to } \\
\text { cement } \\
\text { ratio }\end{array}$ & $\begin{array}{c}\text { Acti-Gel }{ }^{\circledR} \\
\text { (wt\%) }\end{array}$ & 3-day & 5-day & 7-day & 14-day & 21-day & 28-day \\
\hline Batch 1 & 6.5 & 0.72 & 0 & 0.56 & 0.67 & 0.81 & 1.02 & 1.14 & 1.21 \\
Batch 2 & 6.5 & 0.72 & 0.05 & 0.59 & 0.72 & 0.83 & 1.11 & 1.21 & 1.38 \\
Batch 3 & 6.5 & 0.72 & 0.03 & 0.67 & 0.84 & 0.95 & 1.14 & 1.30 & 1.42 \\
\hline
\end{tabular}




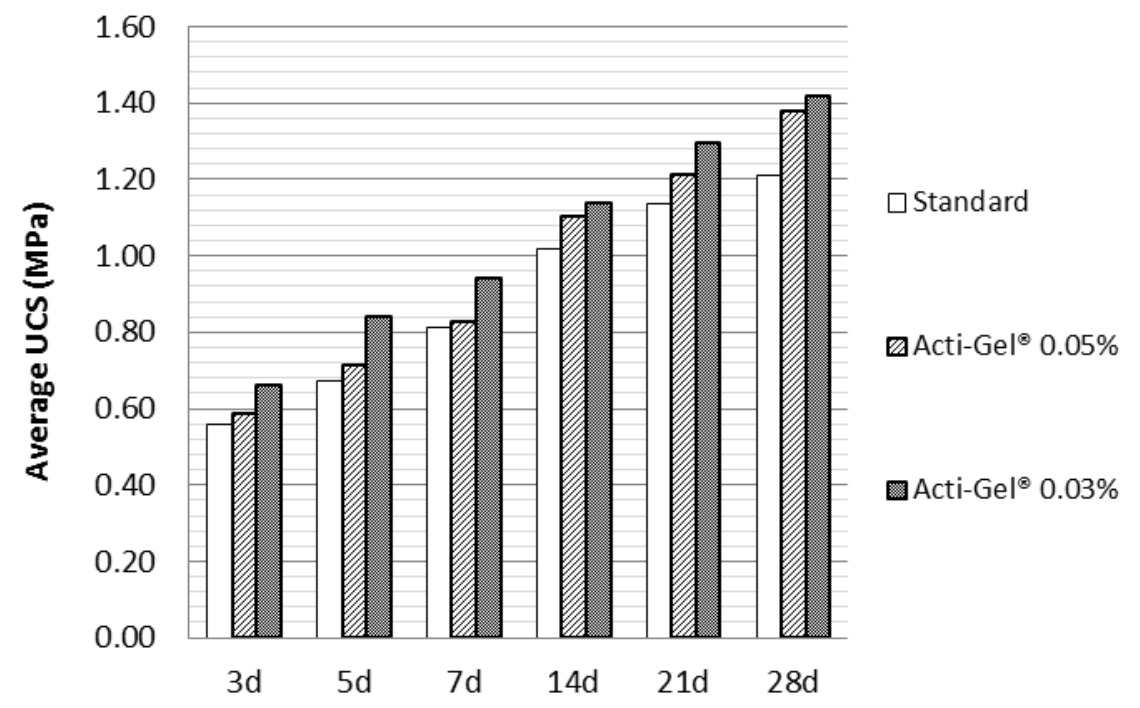

Figure 3 UCS as a function of curing period for paste fill trials

\subsection{Laboratory strength results and discussion - hydraulic fill}

\subsubsection{Effect of Acti-Gelß in the 10:1 higher binder content case}

The UCS as a function of curing time for the first six batches, which were prepared at the higher binder content is shown in Figure 4. It can be seen from the figure that overall for the higher binder content case, in general, the highest strengths were achieved with 0.03 wt\% Acti-Gel $^{\circledR}$, followed by $0.05 \mathrm{wt} \%$ Acti-Gel $^{\circledR}$, and that the batches containing no Acti-Gel ${ }^{\circledR}$ returned the lowest strengths. Even as early as three days, the Acti-Gel ${ }^{\circledR}$ batches generally returned higher UCS values.

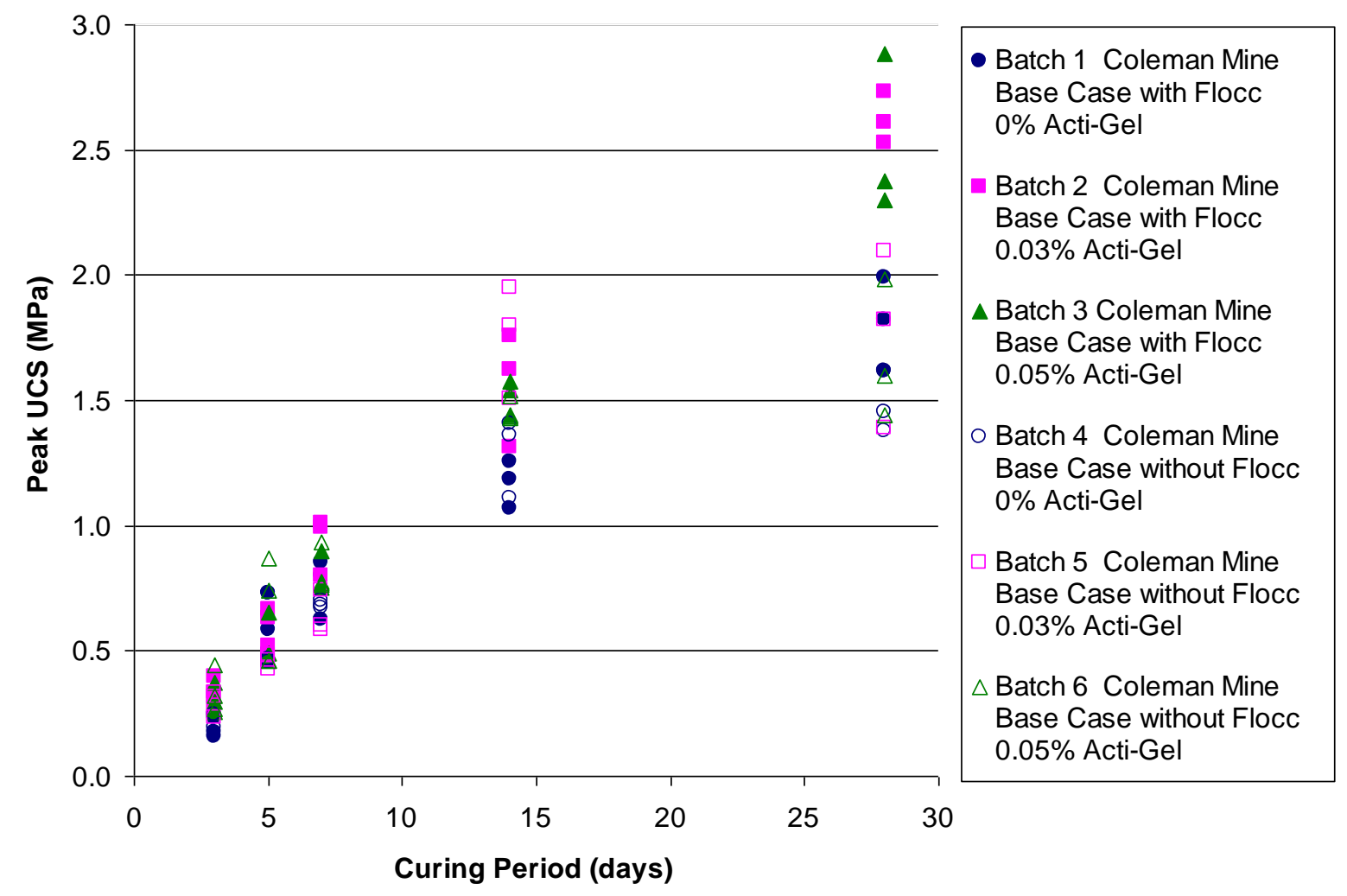

Figure 4 UCS as a function of curing period for higher binder content with/without flocculant 


\subsubsection{Effect of Acti-Gelß in the lower binder content case}

The UCS as a function of curing period for batches 7 through 12, which were prepared at the lower binder content, is shown in Figure 5. It can be seen from the figure that overall for the lower binder content case, in general, the highest strengths were achieved with Acti-Gel ${ }^{\circledR}$ addition, whether it be at a dose of $0.03 \mathrm{wt} \%$ or 0.05 wt\%. On average, the batches containing no Acti-Gel ${ }^{\circledR}$ returned the lowest strengths; however, this was more apparent in the early curing periods. Even as early as seven days, the Acti-Gel ${ }^{\circledR}$ batches generally returned higher UCS values.

\subsubsection{Overall analysis of the effect of Acti-Gelß}

It was found that in general, at dosages of 0.03 and 0.05 wt\%, Acti-Gel ${ }^{\circledR}$ delivered enhanced uniaxial compressive strength. It should be noted that there was a fair amount of variability in the UCS values, especially in the lower binder content batches, and in batches containing no flocculant. The standard deviations are shown in Table 2. It can be seen that in batches prepared at the higher binder content, the standard deviation values were generally greater at later curing periods, and that for batches prepared at both binder contents, on average, the standard deviation values were greater in batches prepared without flocculant addition. Perhaps this indicates that, as would be expected, flocculant addition resulted in less segregation within the mix and/or samples, and therefore returned a lower variability in strength between samples.

Using the average UCS values of each batch, increase in strength was calculated as a percentage of improvement over the base case without the additive (Table 2). The percentage improvement of average UCS for samples with Acti-Gel ${ }^{\circledR}$ versus those without ranged from no improvement to $45 \%$ improvement. In two cases, which were at seven days, the improvement was less than $10 \%$, and in one of these cases it was $-6 \%$. This was from a batch prepared with no flocculant and is believed to be due to variability in UCS results. At 14 days, the improvement ranged from $11-45 \%$, and at 28 days, it ranged from $10-45 \%$ improvement. Improvements of $30 \%$ or greater are highlighted in Table 3. 


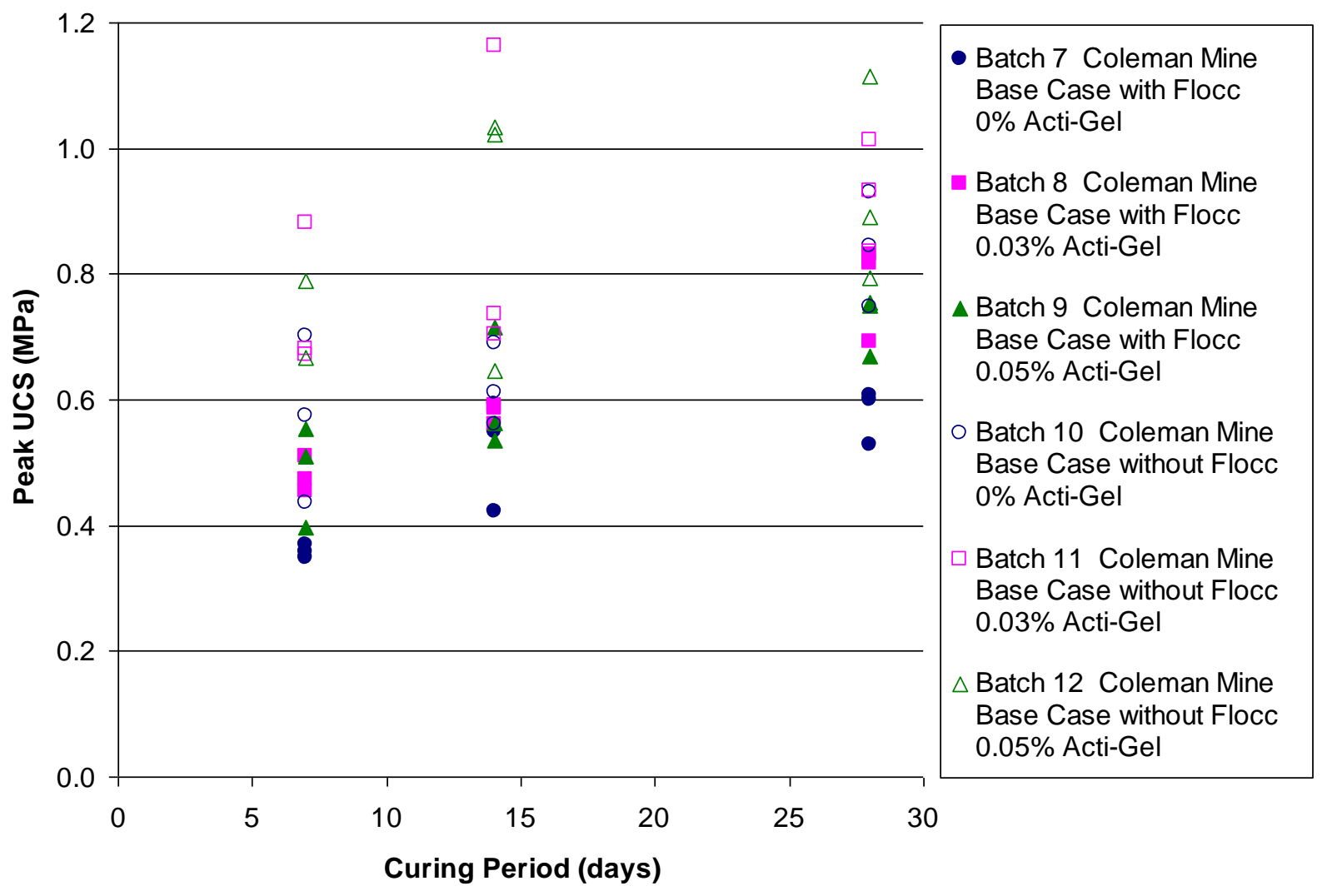

Figure 5 UCS as a function of curing period for the lower binder content with/without flocculant

Table 2 Average UCS test results

\begin{tabular}{|c|c|c|c|c|c|c|c|c|c|}
\hline \multirow[b]{2}{*}{ Batch \# } & \multirow[b]{2}{*}{$\begin{array}{c}\text { Binder } \\
\text { ratio }\end{array}$} & \multirow[b]{2}{*}{ Flocculant } & \multicolumn{7}{|c|}{ Average UCS (MPa) } \\
\hline & & & $\begin{array}{c}\text { Acti-Gel }^{\circledR} \\
(\%)\end{array}$ & 7-day & $\begin{array}{l}\text { 7-day } \\
\text { st. dev. }\end{array}$ & 14-day & $\begin{array}{l}\text { 14-day } \\
\text { st. dev. }\end{array}$ & 28-day & $\begin{array}{l}\text { 28-day } \\
\text { st. dev. }\end{array}$ \\
\hline Batch 1 & Higher & With & 0 & 0.76 & 0.12 & 1.17 & 0.09 & 1.81 & 0.19 \\
\hline Batch 2 & Higher & With & 0.03 & 0.93 & 0.12 & 1.56 & 0.23 & 2.63 & 0.10 \\
\hline Batch 3 & Higher & With & 0.05 & 0.81 & 0.08 & 1.52 & 0.07 & 2.52 & 0.32 \\
\hline Batch 4 & Higher & Without & 0 & 0.69 & 0.01 & 1.29 & 0.16 & 1.48 & 0.12 \\
\hline Batch 5 & Higher & Without & 0.03 & 0.64 & 0.08 & 1.75 & 0.22 & 1.77 & 0.36 \\
\hline Batch 6 & Higher & Without & 0.05 & 0.82 & 0.10 & 1.46 & 0.05 & 1.67 & 0.28 \\
\hline Batch 7 & Lower & With & 0 & 0.36 & 0.01 & 0.52 & 0.09 & 0.58 & 0.04 \\
\hline Batch 8 & Lower & With & 0.03 & 0.48 & 0.03 & 0.58 & 0.02 & 0.78 & 0.08 \\
\hline Batch 9 & Lower & With & 0.05 & 0.49 & 0.08 & 0.60 & 0.10 & 0.72 & 0.05 \\
\hline Batch 10 & Lower & Without & 0 & 0.57 & 0.13 & 0.62 & 0.06 & 0.84 & 0.09 \\
\hline Batch 11 & Lower & Without & 0.03 & 0.74 & 0.12 & 0.87 & 0.26 & 0.93 & 0.09 \\
\hline Batch 12 & Lower & Without & 0.05 & 0.73 & 0.09 & 0.90 & 0.22 & 0.93 & 0.16 \\
\hline
\end{tabular}




\begin{tabular}{|c|c|c|c|}
\hline & \multicolumn{3}{|c|}{$\begin{array}{l}\text { Improvement in average } \\
\text { UCS value }\end{array}$} \\
\hline & 7-day & 14-day & 28-day \\
\hline Higher binder content $-0.03 \%$ Acti-Ge $^{\circledast}$ addition with flocculant & $23 \%$ & $34 \%$ & $45 \%$ \\
\hline Higher binder content $-0.05 \%$ Acti-Gel $^{\oplus}$ addition with flocculant & $6 \%$ & $30 \%$ & $39 \%$ \\
\hline Higher binder content $-0.03 \%$ Acti-Gel $^{\circledR}$ addition without flocculant & $-6 \%$ & $35 \%$ & $20 \%$ \\
\hline Higher binder content $-0.05 \%$ Acti-Gel $^{\circledR}$ addition without flocculant & $20 \%$ & $13 \%$ & $13 \%$ \\
\hline Lower binder content $-0.03 \%$ Acti-Gel $^{\circledR}$ addition with flocculant & $34 \%$ & $11 \%$ & $35 \%$ \\
\hline Lower binder content $-0.05 \%$ Acti-Ge ${ }^{\circledR}$ addition with flocculant & $36 \%$ & $16 \%$ & $25 \%$ \\
\hline Lower binder content $-0.03 \%$ Acti-Gel ${ }^{\oplus}$ addition without flocculant & $30 \%$ & $40 \%$ & $10 \%$ \\
\hline Lower binder content $-0.05 \%$ Acti-Gel ${ }^{\circledR}$ addition without flocculant & $28 \%$ & $45 \%$ & $11 \%$ \\
\hline
\end{tabular}

\subsubsection{Effect of flocculant on strength results}

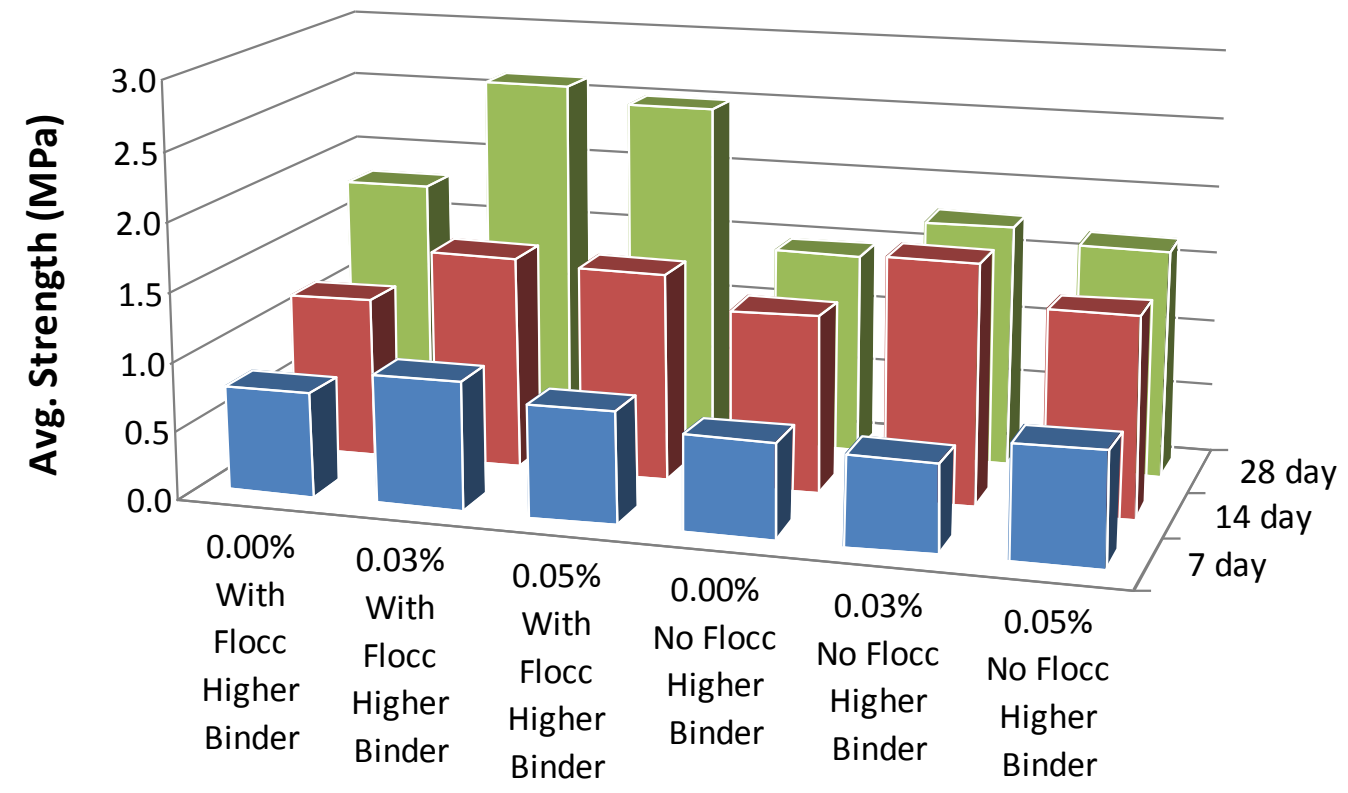

\section{Figure 6 Average UCS for higher binder content as a function of mix details and curing period}

For batches prepared at the higher binder content, in general, and especially at 28 days, the absence of flocculant resulted in lower average UCS values (Figure 6). For batches prepared at the lower binder content, in general the opposite was found it appears that batches prepared without flocculant achieved higher average UCS values (Figure 7). 


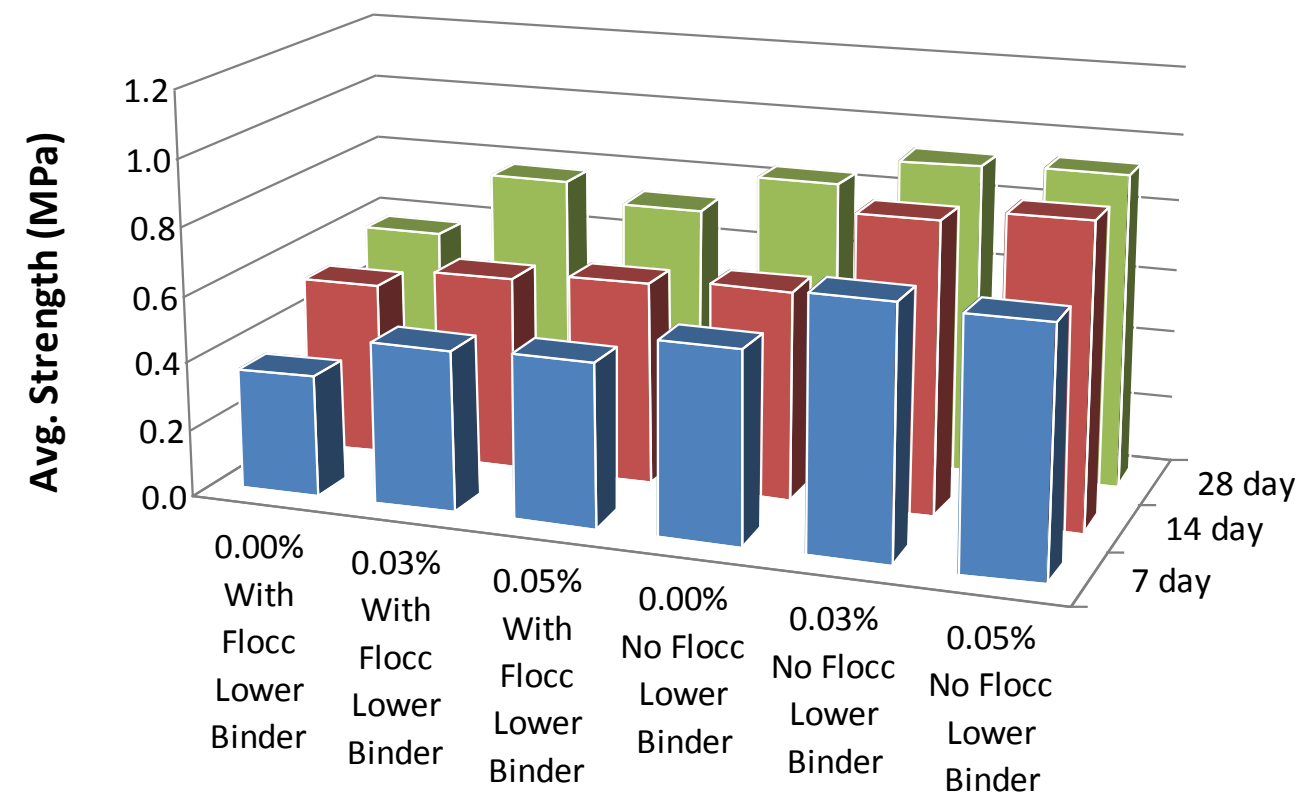

Figure 7 Average UCS for lower binder content as a function of mix details and curing period

\section{$4 \quad$ Flowability properties determination results and discussion}

\subsection{Flowability test results and discussion - paste fill}

The flowability test results for the paste fill trials are shown in Table 4. It can be seen from the flow rates that $\mathrm{Acti}-\mathrm{Gel}^{\circledR}$ addition resulted in a significant increase in flow rate. It was also noted that in the Acti-Gel ${ }^{\circledR}$ tests, the mix was visibly 'creamier' and segregation appeared to be reduced. The increased flow rate and visibly improved flow behaviour leads toward the possibility that an increase in solids in the paste fill mix could be realised with the addition of Acti-Gel ${ }^{\circledR}$.

Table 4 Paste fill flowability test results

\begin{tabular}{|c|c|c|c|c|c|c|c|c|}
\hline \multicolumn{3}{|c|}{ Mixing time } & \multirow{2}{*}{$\begin{array}{l}\text { Slump } \\
(\mathrm{mm})\end{array}$} & \multirow{2}{*}{$\begin{array}{c}\text { Paste } \\
\text { added to } \\
\text { hopper } \\
\text { (kg) }\end{array}$} & \multirow{2}{*}{$\begin{array}{c}\text { Paste in } \\
\text { bucket }\end{array}$} & \multirow{2}{*}{$\begin{array}{r}\text { Time } \\
\text { (s) }\end{array}$} & \multirow{2}{*}{$\begin{array}{l}\begin{array}{c}\text { Flow } \\
\text { rate }\end{array} \\
(\mathrm{kg} / \mathrm{s})\end{array}$} & \multirow[t]{2}{*}{ Comments } \\
\hline Start & Finish & $\begin{array}{l}\text { Time } \\
\text { (min) }\end{array}$ & & & & & & \\
\hline $10: 05 \mathrm{am}$ & $12: 45 \mathrm{pm}$ & 160 & 211 & 69.85 & 7 & 19.2 & 0.36 & Pipe blocked \\
\hline $12: 05 \mathrm{pm}$ & $12: 45 \mathrm{pm}$ & 40 & 216 & 67.3 & 28.45 & 62 & 0.46 & $\begin{array}{c}\text { Free flowed until } \\
\text { pipe was } 3 / 4 \text { empty }\end{array}$ \\
\hline $12: 27 \mathrm{pm}$ & $12: 45 \mathrm{pm}$ & 18 & 227 & 74.3 & 60.1 & 124 & 0.48 & $\begin{array}{l}\text { Free flowed until } \\
\text { pipe was } 3 / 4 \text { empty }\end{array}$ \\
\hline
\end{tabular}

\subsection{Flowability test results and discussion - hydraulic fill}

As testing progressed, it was determined that the original time span being recorded ( 10 seconds) was too long, as a full flow rate was not able to be recorded for all batches. Therefore, it was decided that the time interval was to be reduced to six seconds. Four of the initial five batches were re-tested with the new time interval of 6 seconds to allow for consistent comparison between batches. Upon examination of the video records for each test, it was decided that the determination of flow rates would be most accurately 
performed by viewing the video records at slow speed, with (i) the time interval required to fill the second $20 \mathrm{~L}$ pail, and (ii) the recorded mass of the slurry in the pail, being the determining factors for calculating flow rate. Figures 8 and 9 show the results of the twelve flow trials performed. Some of the trials were repeated, as indicated on the horizontal axes of the figures.

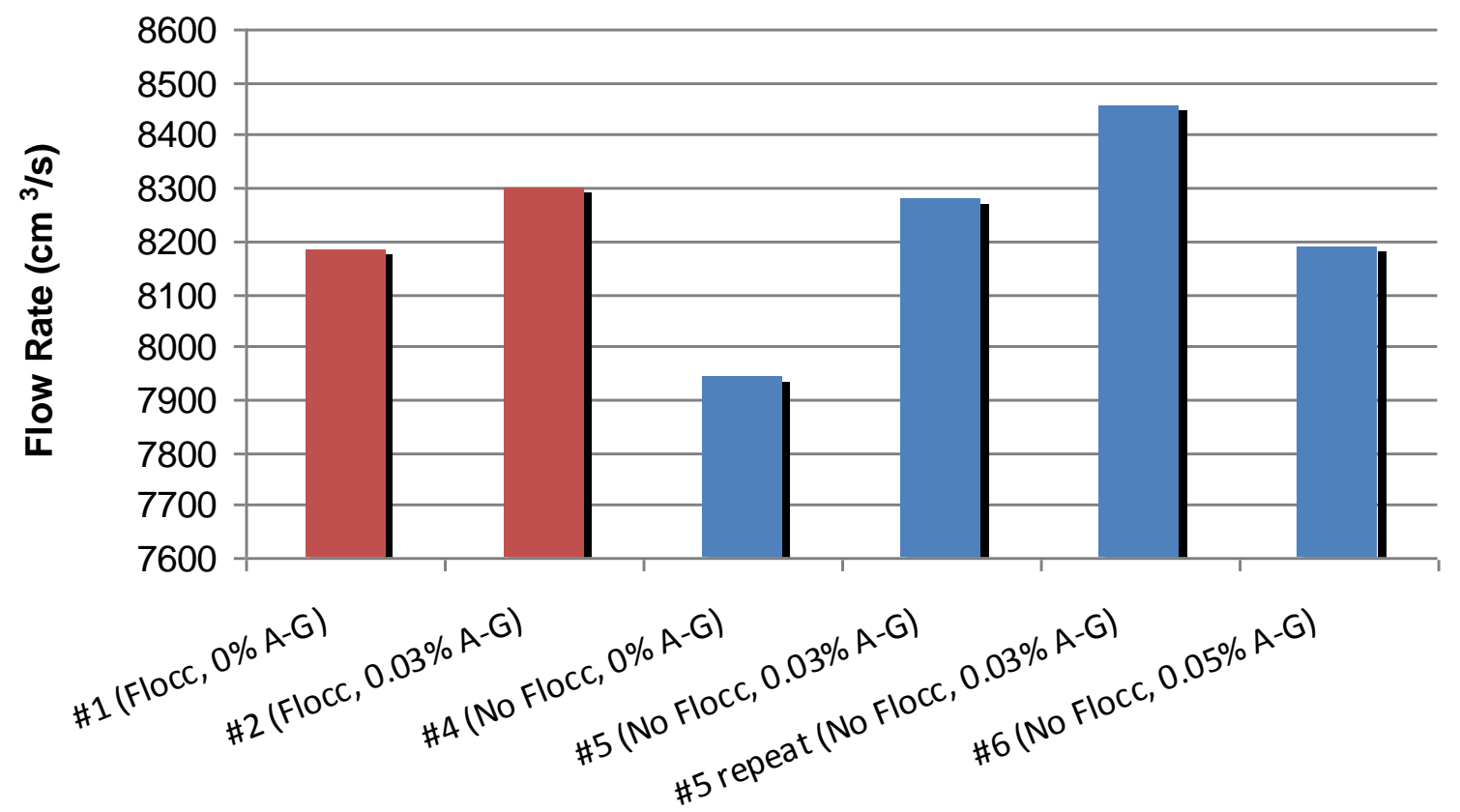

Figure 8 Flow rate results for batches prepared with the higher binder content

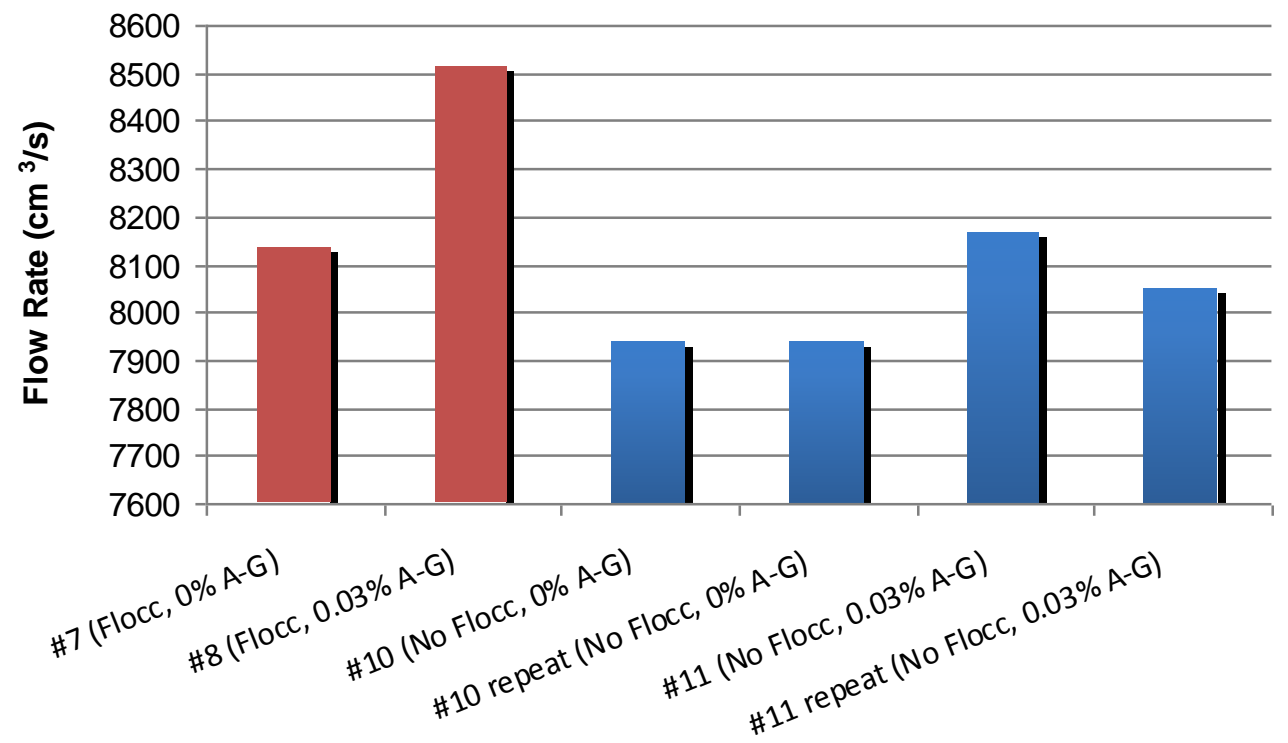

Figure 9 Flow rate results for batches prepared with the lower binder content

It can be seen from the flow rates shown in Figures 8 and 9 that in all cases, 0.03 wt\% Acti-Gel ${ }^{\circledR}$ addition resulted in a slight increase in flow rate. It can also be said that the results seem to show consistency when comparing the repeated batches (batches $5,10,11$ ). The benefit of Acti-Gel ${ }^{\circledR}$ addition in the higher binder content trials was slight in those which also contained flocculant ( $1 \%$ faster flow rate); however, there was a $4-6 \%$ flow rate increase in the batches that did not contain flocculant. It seemed that with the lower binder content, the highest gain in flow rate was in the flocculant batches where a $5 \%$ increase in flow rate was realised. In both binder content cases, the results seem to show that, on average, the use of 0.03 wt $\%$ 
Acti-Gel ${ }^{\circledast}$ without flocculant addition gives similar flow rate values as in the base case trial (hydraulic backfill mix with flocculant used currently at Coleman Mine). This suggests that it is possible that substituting the flocculant for Acti-Gel ${ }^{\circledR}$ at 0.03 wt\% in the current Coleman Mine mix could provide similar flow rates.

It is important to note that the variability of this novel test method for flow rate is unknown at this time. It is recommended that further trials be conducted in an attempt to determine the repeatability of the method. It should also be noted that the determination of collection time, performed by examining the videos at slow speed, was very sensitive; changing the collection time by as little as 1 frame (1/29 of a second) resulted in a notable difference in the calculated flow rate. For instance, in batch 6 (as seen in Figure 6), if the number of frames selected was one less, the difference in flow rate would be an increase of $108 \mathrm{~cm}^{3} / \mathrm{s}$. In future trials, this could be addressed by increasing the quantity of material used per batch by at least double. This would increase the elapsed time of each test considerably and thereby reduce the sensitivity of the collection time determination. Lastly, in some trials, a considerable amount of spillage occurred when transitioning between $20 \mathrm{~L}$ pails. For future tests, it is recommended that a larger vessel with a known volume be filled by a flexible hose. The initial flow material as well as any material discharged after the vessel has filled could then easily be discharged into a separate receptacle.

\section{Cost-effectiveness of addition of Acti-Gelß}

In order to complete a preliminary analysis of the cost-effectiveness of Acti-Gel ${ }^{\circledR}$, it was decided to include another mine, Creighton Mine, in the analysis. The classified tailings used at Creighton Mine were collected, mixed and sampled in the same manner as with the Coleman Mine raw materials. Nine batches of backfill were prepared for UCS testing with the aim of determining the degree to which the overall binder content could be reduced with the addition of 0.03 wt $\%$ Acti-Gel $^{\circledR}$, while maintaining the same UCS. The samples were prepared in the same manner as with the Coleman Mine tests, and the same two binder contents were selected. A total of 132 cylindrical samples were prepared for UCS determination at curing periods ranging from three to 14 days. Since 0.05 wt\% Acti-Gel ${ }^{\circledR}$ did not provide significantly higher strength than $0.03 \mathrm{wt} \%$ in the Coleman Mine trials, it was decided to focus on only zero or $0.03 \mathrm{wt} \%$ in the Creighton Mine trials.

\subsection{Strength results and discussion for the Creighton Mine trials}

\subsubsection{Effect of Acti-Gelß in the higher binder content case - Creighton Mine trials}

The UCS as a function of curing time for the first three Creighton Mine batches, which were prepared at the higher binder content is shown in Figure 10. In general, the highest strengths were achieved with 0.03 wt\% Acti-Gel ${ }^{\circledast}$, and at the later curing period of 14 days, the batch prepared with both Acti-Gel ${ }^{\circledast}$ and flocculant returned the highest strengths.

\subsubsection{Effect of Acti-Gel® in the lower binder content case - Creighton Mine trials}

The UCS as a function of curing period for batches 4 to 6 , which were prepared at the lower binder content, is shown in Figure 11. It can be seen from the figure that overall for the lower binder content case, the highest strengths were achieved with Acti-Gel ${ }^{\circledR}$ addition, whether it be with or without flocculant. On average, the batches containing no Acti-Gel ${ }^{\circledR}$ returned the lowest strengths; however, this was more apparent in the early curing period of seven days.

\subsubsection{Effect of Acti-Ge/® addition on reduced binder content samples - Creighton Mine trials}

A further three batches were prepared at a reduced binder content in order to determine the degree to which the binder content of Creighton Mine's bulk pour recipe could be reduced with the addition of 0.03 wt\% Acti-Gel ${ }^{\circledR}$, while maintaining the same UCS. Figure 12 shows the 14-day results directly comparing the base case for bulk pouring with no Acti-Gel ${ }^{\circledR}$ to the proposed case for bulk pouring of reduced binder 
content with $0.03 \mathrm{wt} \% \mathrm{Acti}^{-G e l}{ }^{\circledR}$ (these two cases are circled on the graph). It was found that by adding Acti-Gel ${ }^{\circledR}$, UCS was maintained even with the reduction in binder content. It can also be seen that, in general, samples containing Acti-Gel ${ }^{\circledR}$ prepared without flocculant returned slightly higher strengths than those prepared with flocculant.

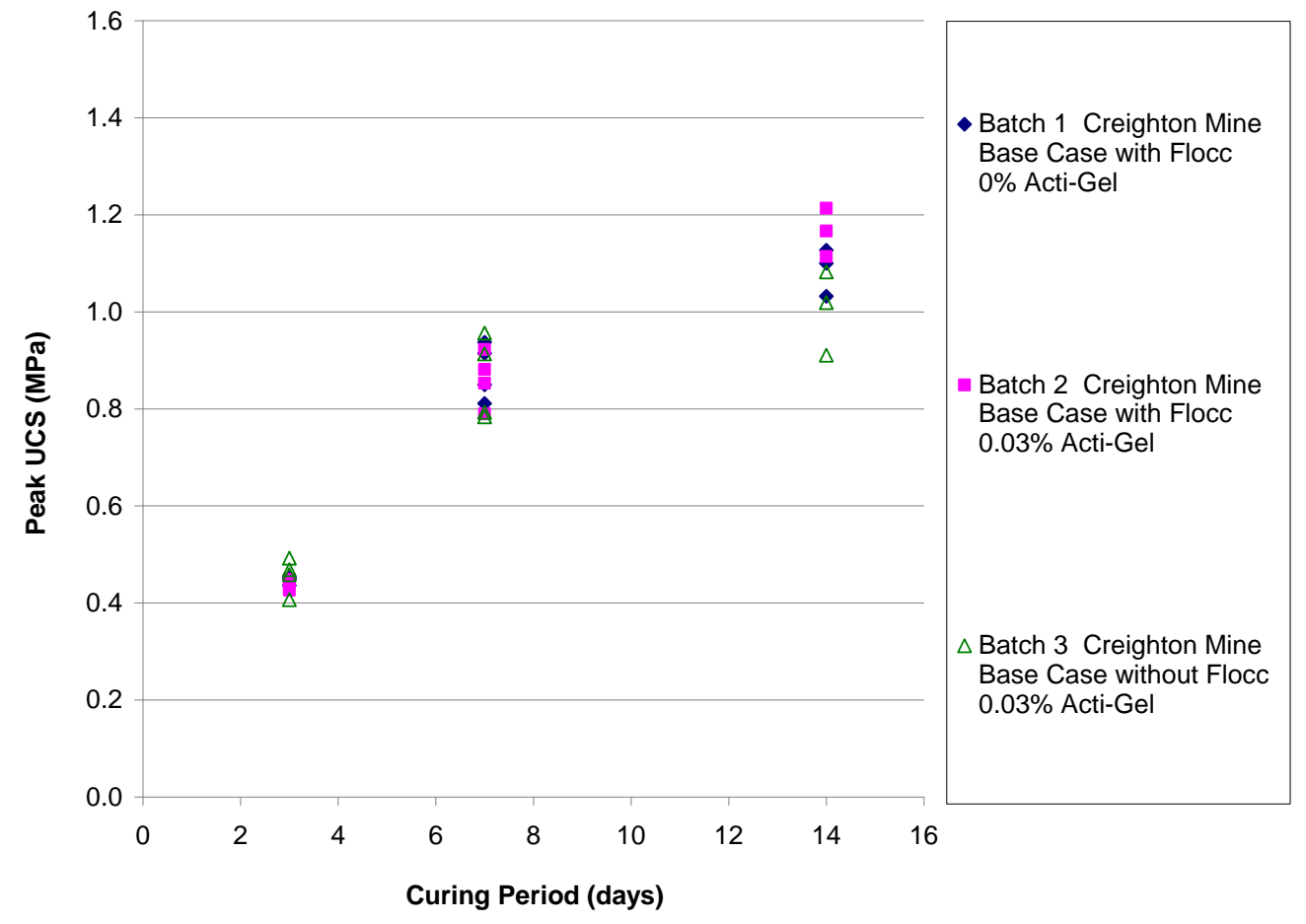

\section{Figure 10 UCS as a function of curing period for the higher binder content with/without flocculant - Creighton Mine trials}

The possible annual cost savings of such a binder reduction at Creighton Mine were explored, assuming a yearly fill tonnage of 500,000 . Noting that the reduced binder samples containing Acti-Gel ${ }^{\circledR}$ and also containing no flocculant returned strengths as high as those that did contain flocculant, perhaps a savings could be realised by a reduction, if not an elimination, of flocculant. The resulting potential savings for a 500,000 t operation were determined to be approximately CAD 165,000 per year. 


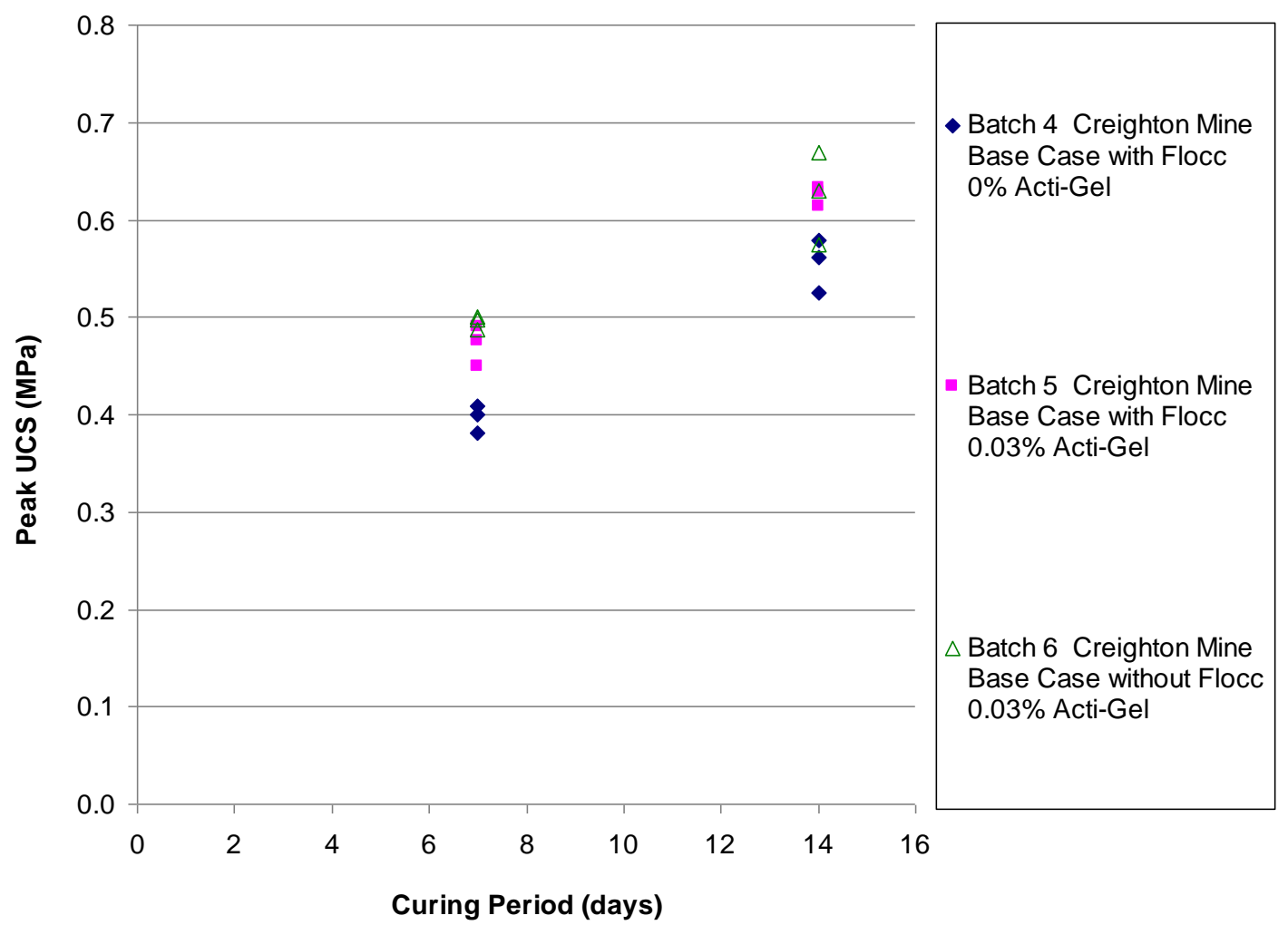

Figure 11 UCS as a function of curing period for the lower binder content with/without flocculant - Creighton Mine trials

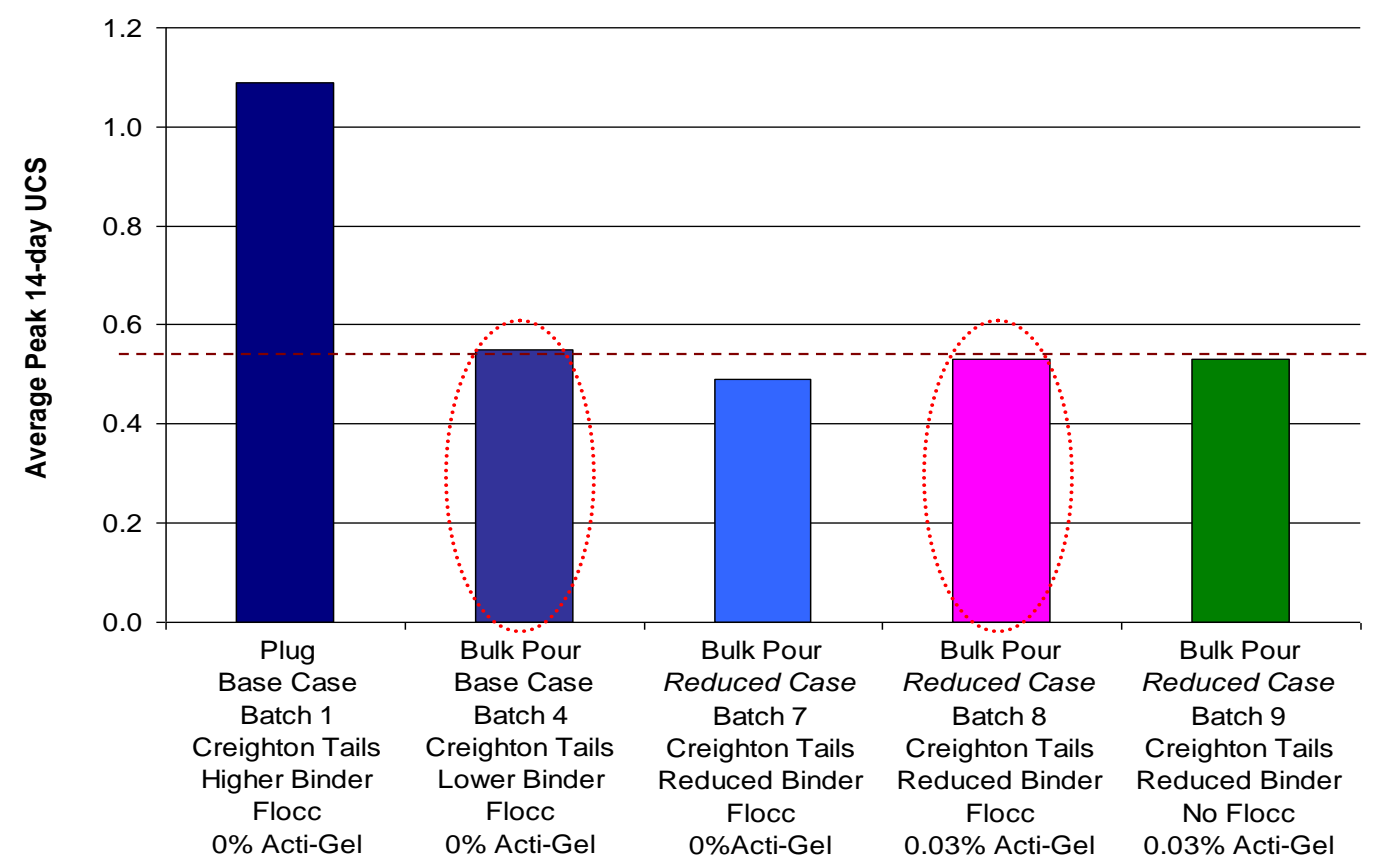

Figure 12 14-day average UCS directly comparing bulk pour base case and reduced binder content case - Creighton Mine trials

\subsection{Further discussion on cost-effectiveness for the Coleman Mine operation}

The results of this laboratory study suggest that the potential benefits of Acti-Gel ${ }^{\circledR}$ could be greater with the Coleman Mine raw materials because the strength increase with Acti-Gel ${ }^{\circledR}$ and Coleman Mine materials was notably greater than that with Creighton Mine raw materials. Therefore, using the UCS data from the 
Coleman Mine trials, it was determined by linear interpolation, as shown in Table 5, that it appears the higher plug pour binder content could potentially be reduced by approximately $2 \mathrm{wt} \%$ and still maintain strength with the addition of $0.03 \mathrm{wt} \%$ Acti-Gel $^{\circledR}$. The possible annual cost savings of such a binder reduction at Coleman Mine, again assuming a yearly fill tonnage of 500,000, were determined to be close to CAD 500,000 per year.

\section{Table 5 Determination of equivalent binder ratio by linear interpolation}

\begin{tabular}{lcccccc}
\hline Batch \# & $\begin{array}{c}\text { Percent binder } \\
\text { reduction }\end{array}$ & $\begin{array}{c}\text { Acti-Gel } \\
\text { (\%) }\end{array}$ & 7-day & 14-day & 28-day & \\
\hline Batch 1 & $0.0 \%$ & $0.00 \%$ & 0.76 & 1.17 & 1.81 & Baseline values (target) \\
Batch 2 & $0.0 \%$ & $0.03 \%$ & 0.93 & 1.56 & 2.63 & \\
Batch 3 & $1.4 \%$ & $0.03 \%$ & 0.79 & 1.25 & 2.03 & \\
Batch 4 & $1.9 \%$ & $0.03 \%$ & 0.73 & 1.12 & 1.79 & \\
Batch 5 & $2.8 \%$ & $0.03 \%$ & 0.64 & 0.92 & 1.41 & \\
Batch 6 & $3.8 \%$ & $0.03 \%$ & 0.53 & 0.69 & 0.99 & \\
Batch 7 & $4.8 \%$ & $0.03 \%$ & 0.48 & 0.58 & 0.78 & \\
\hline
\end{tabular}

\section{Conclusions}

It was found that in general, at dosages of 0.03 and 0.05 wt\%, Acti-Gel ${ }^{\circledR}$ delivered enhanced uniaxial compressive strength, in both paste and hydraulic fill trials. It should be noted that in the hydraulic fill trials, there was a fair amount of variability in the UCS values, especially in the lower binder content, bulk pour batches, and in batches containing no flocculant.

It is important to note that the variability of the novel test method for flow rate is unknown at this time. It is recommended that further trials be conducted in an attempt to determine the repeatability of the method. It was found from the flow rates tests that in all cases, Acti-Gel ${ }^{\circledR}$ addition resulted in significantly improved flow rates in the paste fill trials. For the hydraulic fill trials, in all cases, 0.03 wt\% Acti-Gel ${ }^{\circledR}$ addition resulted in a slight increase in flow rate. The results seem to show consistency when comparing repeated batches. The benefit of Acti-Gel ${ }^{\circledR}$ addition in the plug pour, higher binder content trials was slight in those which also contained flocculant (1\% faster flow rate); however, there was a $4-6 \%$ flow rate increase in the batches that did not contain flocculant. It seemed that with the lower binder content, the highest gain in flow rate was in the flocculant batches where a $5 \%$ increase in flow rate was realised. In both the binder content cases, the results seem to show that, on average, the use of 0.03 wt\% Acti-Gel ${ }^{\circledR}$ without flocculant addition gives similar flow rate values as in the base case trial (hydraulic backfill mix with flocculant used currently at Coleman Mine). This suggests that it is possible that substituting the flocculant for Acti-Gel ${ }^{\circledR}$ at 0.03 wt\% in the current Coleman Mine mix could provide similar flow rates.

It was determined that, for a 500,000 t per year operation, a potential annual savings of approximately CAD 165,000 could result if Acti-Gel ${ }^{\circledR}$ were implemented at the Creighton Mine Operation. It was also determined, based on interpolation from UCS data, that with reduced binder content and $0.03 \mathrm{wt} \%$ Acti-Gel ${ }^{\circledR}$ at the Coleman Mine Operation, assuming again a 500,000 t per year operation, there could be a potential annual savings of close to CAD 500,000. A stope-by-stope analysis is recommended in order to refine these cost savings estimations.

The cost-benefit analysis for the Creighton Mine operation was based on 14-day UCS data, and it is therefore planned that the 28-day UCS results from the Creighton Mine trials be reviewed to ensure similar trends as the curing period increases beyond 14 days. It is planned for the near future that a further 
12 batches for UCS determination be prepared using Coleman Mine materials, including batches prepared at various lower binder contents, in an effort to determine if the interpolated reduced binder content could, in fact provide sufficient strength with the addition of $0.03 \mathrm{wt} \%$ Acti-Gel $^{\circledast}$. It is also recommended that longer term UCS tests for the paste fill operation, and for both hydraulic fill operations be conducted to ensure that sample integrity remains beyond 28 days. It should be noted that a possible reduction and/or elimination in flocculant use at Vale's Creighton Mine operation was suggested in this paper as a potential option; however, sufficient laboratory and field trials have not been undertaken to confirm this as a viable option at this time.

\section{References}

Ackim, M 2011, 'Development of a suitable mine backfill material using mine waste for safe and economical ore production at Konkola Mine (Zambia)', Masters dissertation, The University of Zambia.

Benzaazoua, M, Marion, P, Picquet, I \& Bussière, B 2004, 'The use of paste fill as solidification and stabilization process for the control of acid mine drainage', Minerals Engineering, vol. 17, no. 2, pp. 233-243.

Hartman, HL, Britton, SG, Gentry, DW, Karmis, M, Mutmansky, JM, Schlitt, WJ \& Singh, MM 1992, SME Mining Engineering Handbook, 2nd edn, Society for Mining and Metallurgy \& Exploration, Littleton.

Tariq, A \& Yanful, EK 2013, 'A review of binders used in cemented paste tailings for underground and surface disposal practices', Journal of Environmental Management, vol. 131, pp. 138-149.

Wang, X-M, Zhao, J-W, Xue, J-H \& Yu, G-F 2011, 'Features of pipe transportation of paste-like backfilling in deep mines', Journal of Central South University of Technology, vol. 18, no. 5, pp. 1413-1417. 
